Article

\title{
Structural Health Monitoring System for Snow and Wind Load Measurement
}

\author{
Bogdan Dziadak 1
}

Institute of Theory of Electrical Engineering, Measurement and Information Systems, Faculty of Electrical Engineering, Warsaw University of Technology, 00-662 Warsaw, Poland; bogdan.dziadak@ee.pw.edu.pl

Received: 29 February 2020; Accepted: 31 March 2020; Published: 3 April 2020

\begin{abstract}
This article presents a system for monitoring the load caused by strong winds and snow on buildings' roofs. An estimation of the total load on the structure is obtained by measuring the strain on the main roof girders. The system is based on a wireless sensor network structure. The measurement node uses metal strain gauges and strain sensors based on conductive carbon polymers. The application of such sensors allowed us to achieve a measurement resolution of 5.5 ustrain. The node is managed by an Atmeg8A microcontroller. The use of energy saving modes allows for a battery life of 6 months.
\end{abstract}

Keywords: structural health monitoring; strain measurement; wireless sensor networks; strain sensors; polymer sensors

\section{Introduction}

Climatic anomalies have always been observed in various latitudes. However, in recent years, some disturbing weather events have been observed, related to climate change. In addition to the increase in average air temperature, rapid and heavy snowfall combined with strong blowing winds have also been observed in regions where it has not previously been recorded on this scale. An example of this is the snowfall observed in 2015, 2019 and 2020 in Spain and Greece. These situations are dangerous and make life very difficult for the inhabitants of a given region. However, it should be remembered that buildings whose construction parameters do not provide for such loads pose a deadly threat. In regions where high snow loads are obvious (sub-mountainous regions or Scandinavian countries), the buildings' structures are designed for significant snow loads. In countries with occasional snow, other roof structure loads are assumed and, as a consequence, abnormal weather conditions result in damage to the structure of buildings or even their collapse [1].

Analyzing the places where construction disasters occur, it can be concluded that they depend mainly on weather conditions - that is, the amount of snowfall and winds in a given region during the period under consideration. Interestingly, the occurrence of these disasters does not depend on the wealth of a given country or region. Taking the above into account, it can be concluded that in order to increase the safety of buildings and their occupants and to minimize the negative effects associated with the impossibility of the use of buildings, it is necessary to use systems monitoring the load on the structure.

The installation of structural health monitoring systems is cost-intensive and therefore not all buildings are equipped with such systems. The monitoring is mainly carried out on facilities for which the consequences of malfunctioning are considerable. The classification of buildings in this respect is included in the EN 1990-2002 standard. [2,3] and presented in Table 1. 
Table 1. Classes of consequences for buildings according to EN 1990-2002.

\begin{tabular}{ccc}
\hline $\begin{array}{c}\text { Consequences } \\
\text { Class }\end{array}$ & Description & Example of Buildings \\
CC3 & $\begin{array}{c}\text { High } \\
\text { Consequences for loss of human life or economic, } \\
\text { social, environmental consequences very great } \\
\text { Medium }\end{array}$ & $\begin{array}{c}\text { Public buildings, stadiums, } \\
\text { center halls }\end{array}$ \\
CC2 & $\begin{array}{c}\text { Consequences for loss of human life or economic, } \\
\text { social, environmental consequences considerable } \\
\text { Low }\end{array}$ & $\begin{array}{c}\text { Residential and office buildings } \\
\text { CC1 }\end{array}$ \\
$\begin{array}{c}\text { Consequences for loss of human life or economic, } \\
\text { social, environmental consequences considerable } \\
\text { small and negligible }\end{array}$ & $\begin{array}{c}\text { Agricultural buildings, storage } \\
\text { buildings, silos, } \\
\text { greenhouses }\end{array}$ \\
\hline
\end{tabular}

Buildings with a steel load-bearing frame and flat roof belong to category $\mathrm{CC} 1$ or $\mathrm{CC} 2$, since these are mainly storage and agricultural buildings. However, large stores, which also belong to category CC3, also use this construction. Thus, monitoring of the condition of the buildings is desirable as it always improves the safety of the occupants and minimizes the cost of building maintenance (snow clearance), which is important for both large and small businesses.

The article will present a system for monitoring the load of the roof caused by adverse weather conditions such as heavy precipitation and wind. An overview of the currently used methods for measuring snow load on roofs will be briefly presented. Then, our system, allowing for the continuous monitoring of stresses on roof structures, will be presented. The snow load measurement method uses the relationship between the maximum beam deflection and the force causing it. Strain gauges are used to measure the relative elongation of the structure, which is transferred to the deflection and this, in turn, is transferred to the uniform load. The system structure and function blocks will be discussed. The results of the tests will also be analyzed, with particular emphasis on the parameters of sensors based on conductive carbon polymers. The benefits of the system implementation and the directions of further scientific research will be summarized.

\section{Methods of Measuring Snow Load and Wind Speed}

In Central, Eastern Europe and Scandinavia the problem of snow load on buildings is important. In Europe, there are construction standards EN-1991-1-3 [4] based on statistical indicators of snow exposure in the regions concerned. On the basis of these data, roofing structures are designed for which the snow load can be calculated from Formula (1).

$$
S=\mu_{i} \cdot \mathrm{C} w \cdot \mathrm{Ct} \cdot s_{k}
$$

where:

- $\quad \mu_{i}$ is the roof form factor (0.8 to 2.0$)$;

- $s_{k}$ is the characteristic value of snow load on the ground, depending mainly on the altitude above sea level (for Poland, it is from 0.7 to $2.0 \mathrm{kN} / \mathrm{m}^{2}$ );

- $\quad C w$ is the wind exposure factor from 0.8 (set to wind) to 1.2 (sheltered from wind);

- $\mathrm{Ct}$ is the thermal coefficient, generally assumed to be 1.0, depending on the thermal permeability of the roof.

However, it should be remembered that even properly designed structures can collapse due to unfavorable weather conditions. Table 2 shows the data of the Central Office of Building Control (Poland), showing the causes of construction disasters over 5 years. 
Table 2. Causes of construction disasters in Poland [5].

\begin{tabular}{ccccc}
\hline Year & Snow & Rain & Wind & Other \\
\hline 2018 & 1 & 9 & 74 & 165 \\
2017 & 3 & 144 & 428 & 52 \\
2016 & 2 & 18 & 189 & 158 \\
2015 & 7 & 88 & 154 & 64 \\
2014 & 8 & - & 49 & 152 \\
\hline
\end{tabular}

As the results from the data provided, the most common cause of construction disasters is strong wind. However, an indirect cause is the static loading of the structure by snow. Additionally, flat roofs, i.e., roofs in which the roof slope inclination angle changes between 5 and 33 degrees, are the most frequent cause of disasters. On such roofs, the conditions for depositing layers of snow are favorable, because the roof slope angle is insufficient for spontaneous snow slide. This results in the rapid formation of snow embankments and long-lasting on the building. This may cause the roof load to be exceeded. This leads to the collapse of the roof trusses and destruction of the roof covering and, if the supporting structure is broken, to the collapse of the entire building.

Snow cover monitoring is a method of measuring the static load on the structure, which allows us to estimate the permissible dynamic load caused by strong winds. The following can be used for monitoring snow deposits on roofs.

- Snow gauge: the measurement of snow thickness is carried out by means of a graduated rod, which is driven each time or mounted on the roof surface (Figure 1a);

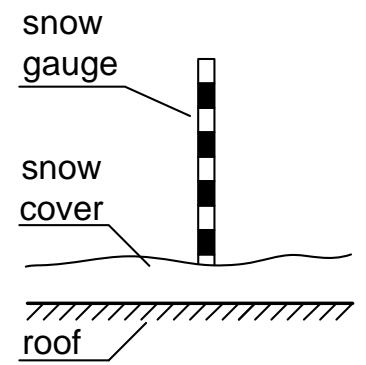

(a)

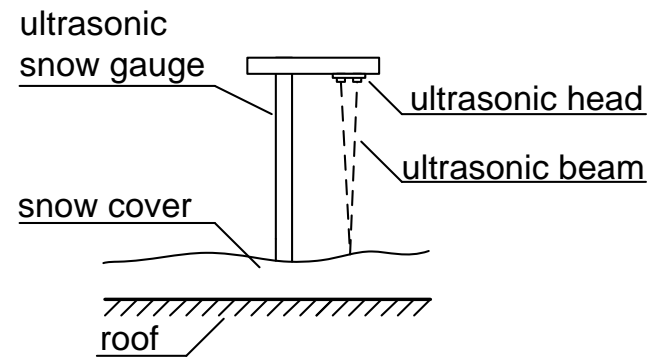

(b)

Figure 1. Examples of instruments for measuring depth of snow in situ, (a) snow gauge, (b) ultrasonic snow depth sensor.

- Ultrasonic snow depth sensor: the measurement is carried out by ultrasonic measurement of the distance from the ultrasonic head placed at a known height to the snow cover (Figure 1b). In both methods, we can only measure the thickness of the snow, without the possibility to determine its mass;

- Snow weight: the measurement of masses of snow is made directly by the placement of an electronic weight with a known surface, on the roof. This solution does not require taking a sample and gives an immediate load result scaled in $\left(\mathrm{kg} / \mathrm{m}^{2}\right)$.

Methods based on ultrasonic technology were used to measure depth of snow even on the ground, in Europe and Alaska [6,7]. However, snow cover monitoring of large areas is mainly based on Synthetic Aperture Radar SAR-type scanning [8,9], or satellite mapping [10,11]. This makes it possible to obtain coverage maps and forecasts for regions or even entire countries.

Anemometers with a rotary head are typically used to monitor wind speed, and were presented in a system for sea level monitoring [12]. Ultrasonic anemometers are also used, where the time of ultrasonic beam passage in the orthogonal system of four heads is measured. Such sensors can be used to measure wind speeds from very low speeds below $1 \mathrm{~m} / \mathrm{s}$ [13] to $90 \mathrm{~m} / \mathrm{s}$ [14]. 
The above methods (except satellite) are used to monitor the condition of buildings in structural heath monitoring systems. An example of such systems is the monitoring of the condition of the football stadium in Brag (Portugal) by means of the WSN presented in [15]. A similar solution for monitoring the roof of a hospital in Rome with 19 nodes and GPS support was presented by Basili et al. in [16]. There is also a visible trend of integration of different systems supporting building maintenance into the system in the IoT ideology [17]. Such an approach increases the choice of hardware and software platforms and gives greater flexibility in facility management by users.

\section{Structure of the Roof Load Monitoring System}

The presented system is used to measure static and dynamic loads of the building structure. It is dedicated to monitor loads occurring on flat roofs (inclination of less than 30 degrees). The assessment of loads is made by measuring the deflection of main girders. Based on the knowledge of structural parameters such as dimensions and shape of the truss, spans, girders, knowledge of roof material parameters (Young's modulus, inertia coefficients), the current strain of roof structure is calculated. The explanation of the measurement method is provided in Section 4 . The system structure is shown in Figure 2.

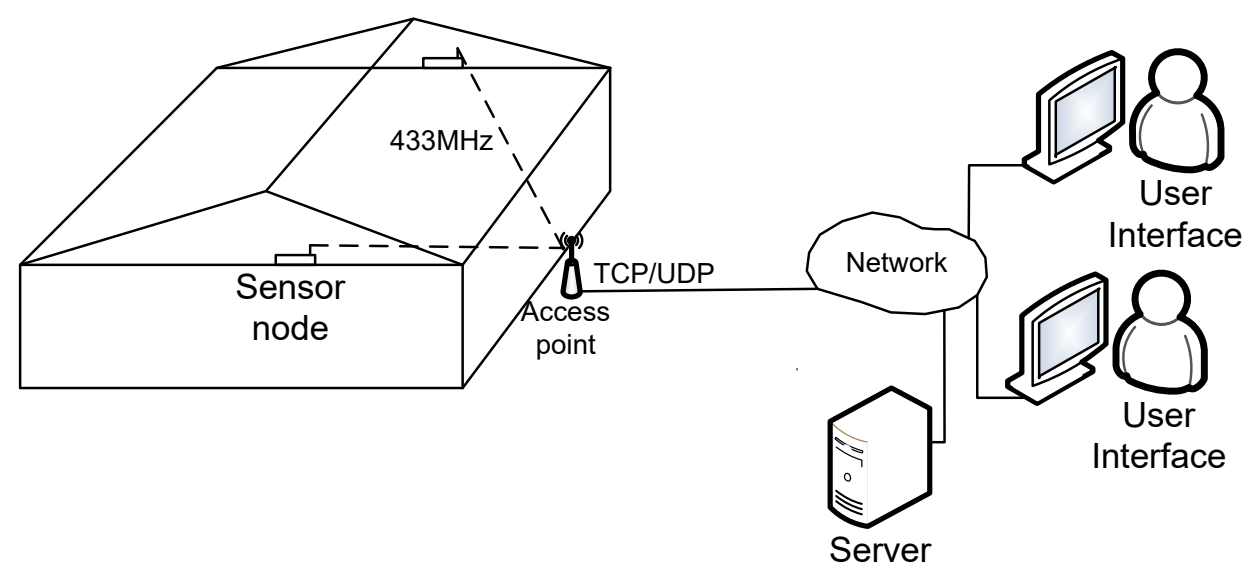

Figure 2. Schematic structure of system for monitoring load of the roof.

The measuring element is a wireless sensor node mounted at the measuring point. The data is wirelessly transmitted to the access point, which is supposed to receive data from all measuring nodes and send it to the main system controller. The TCP/UDP protocol is used for this purpose. The central controller is a server and database. The main task of the server is to receive information from the concentrators, archive the results, process them and present them to the user in the form of dynamic websites. The system user has a current view of the stress distribution on a selected node in the observation window. He can also view the history of measurements and select the number of nodes from which he wants to observe the measurements. The functional blocks of the sensor node are presented in Figure 3. 


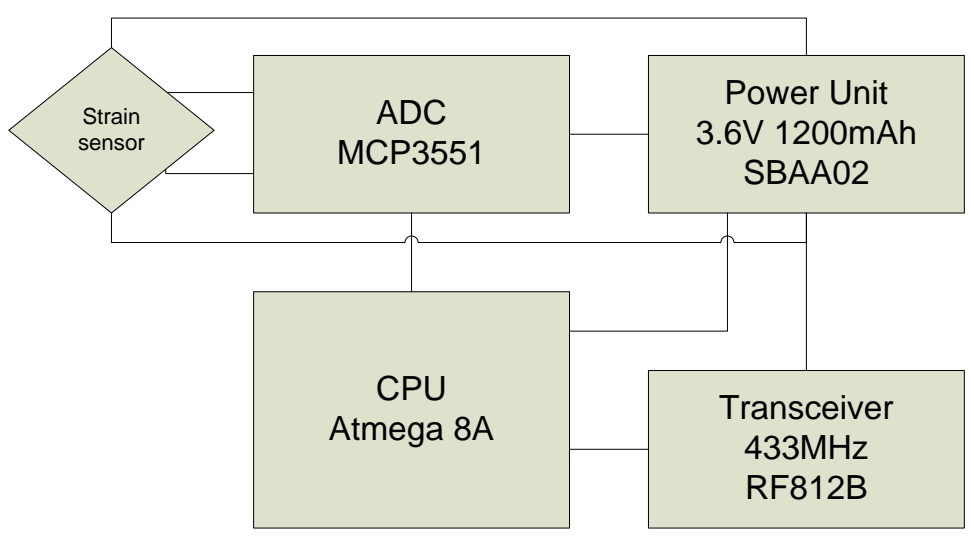

Figure 3. Sensor node structure.

The basic system for measuring strain gauges is the Wheatstone bridge. After a case study [18], a half-bridge differential was determined. In the node, the Wheatstone bridge works as an unbalanced bridge and is treated as a transducer of resistance to voltage changes. Thanks to the half-bridge circuit, we have achieved twice as much sensitivity and, more importantly, a self-reducing temperature error.

Two types of strain gauges were checked. First, foil strain gauges made of constants with a strain gauge constant equal to $K=2.15$, base resistance $120 \mathrm{Ohm}$ and base length of $10 \mathrm{~mm}$ (Figure 4a) were checked. The second type of strain gauges were sensors made with carbon polymer Bare Conductive Electric Paint/UK (Figure 4b). The dimensions of this sensor are $2 \times 20 \mathrm{~mm}$.

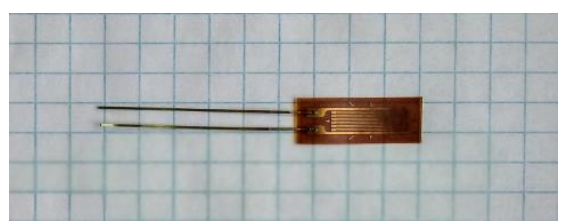

(a)

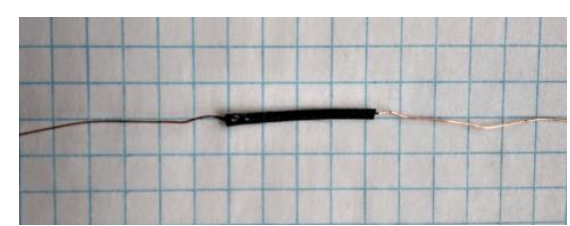

(b)

Figure 4. Strain gauge placed on a $5 \times 5 \mathrm{~mm}$ graduated base, (a) metallic on the foil, (b) polymer on the paper.

The signal from the bridge circuit is applied to the 22-bit MCP355 analog-to-digital converter (ADC), which allows voltage sampling at a frequency of 12 samples per second. Actual measurements are made at a frequency of one every $10 \mathrm{~s}$. The resolution is limited to 20 bits. The digital signalgoes to the Atmega 8A AU1731 microcontroller via the Serial Peripheral Interface (SPI) interface. In the controller, the measurement value is checked with an alarm threshold, and if the threshold value is not exceeded, the next measurement is made. Then, the data package is transmitted once per minute. If the alarm threshold is exceeded, the data is sent to the network hub immediately. The controller's task is also the appropriate formatting of the measurement data to be sent (assigning identifiers and time stamps) and the manage of the transmission.

The measurement data is sent to the network hub using RFM12B. It is an integrated transceiver working in the ISM band, on a 433MHz frequency [19]. This circuit allows for data transmission with a throughput of $115 \mathrm{kbps}$. In a system with an integrated antenna, communication is possible over distances up to $200 \mathrm{~m}$ in free space and $50 \mathrm{~m}$ inside buildings. This enables the monitoring of buildings with an area up to $2500 \mathrm{~m}^{2}$. This distance can be achieved at $19.2 \mathrm{kbps}$ and $1 \mathrm{dBm}$ transmission power, and such values have been implemented in the system. Photos of the real sensor node are presented in Figure 5a. 


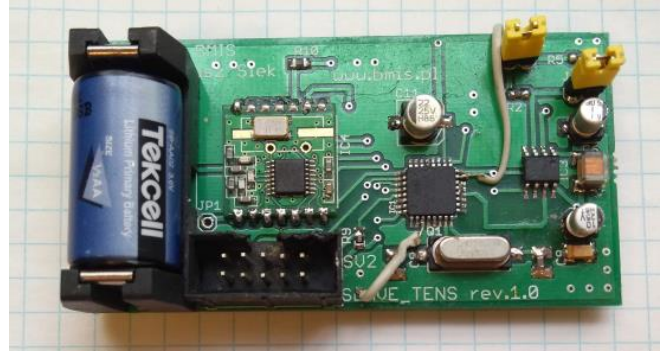

(a)

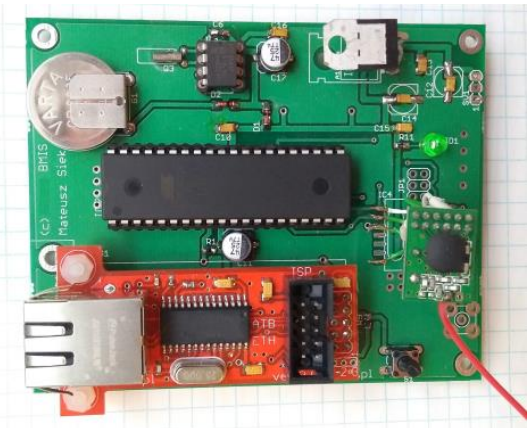

(b)

Figure 5. Elements of the system, (a) wireless sensor node (dimension $75 \times 44 \mathrm{~mm}$ ), (b) access point (dimension $100 \times 80 \mathrm{~mm}$ ).

The task of the access point is to collect data from all measurement nodes and deliver them to the server using TCP/UDP protocol. The access point is powered from the power network and has access to the local LAN network; for communication between them, the ENC28J60SO module was used. The real access point is shown in Figure $5 b$.

The database server works on Linux, using the Ubuntu Server distribution. The user interface is supported by the web server. Apache is installed on a given operating system. An example of a user interface view, showing the structure of the monitored building, the arrangement of sensor nodes, and a tabular visualization of stresses, is shown in Figure 6.

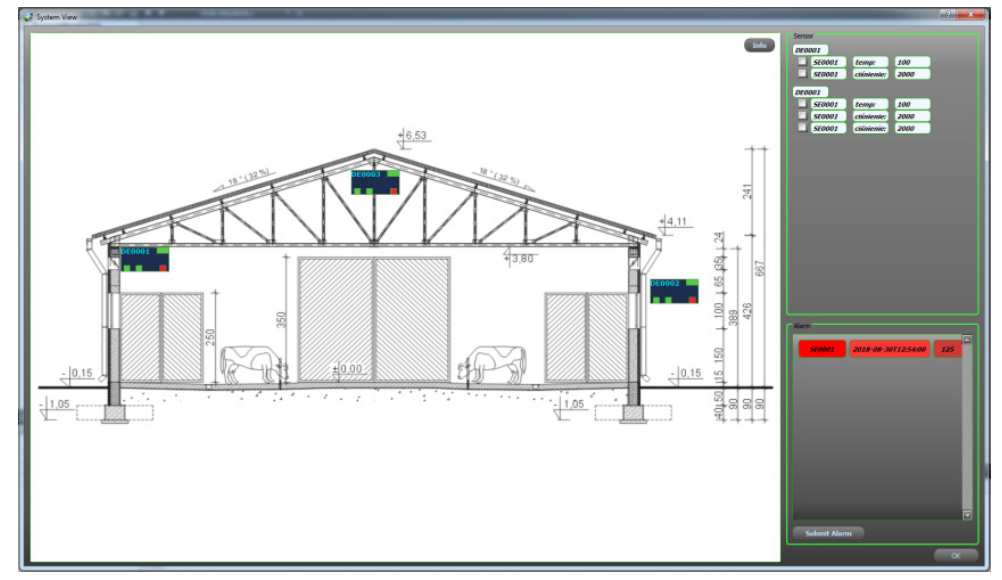

Figure 6. Part of the user interface.

\section{Method and Assumptions}

The interpretation of the obtained results requires a step-by-step explanation of the method for calculating the elongation and load of the roof. A computational experiment will also be carried out to estimate the required resolution of the measuring strain.

Consider a roof structure in which the main girder is supported at the ends (Figure 7). The snow load causes deflection (f max). Such a situation can be modeled by loading the straight beam $[20,21]$. Considering the elementary section of the beam (Figure 8). 


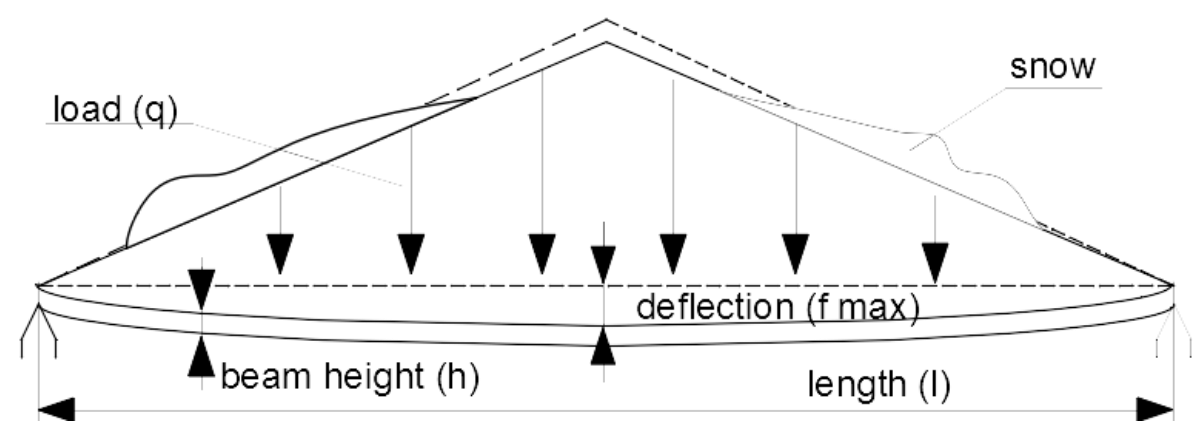

Figure 7. Changing dimensions of the roof under load, solid line: size under load of snow, dash line: size without load.

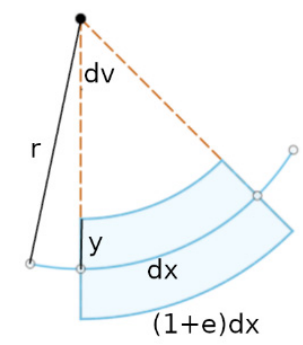

Figure 8. Elementary section of the beam.

As a result of the deformation of the beam, its adjacent sections rotate about an axis perpendicular to the drawing plane. This allows us to write Equation (2).

$$
\frac{(1+e) d x}{-r+y}=\frac{d x}{-r}
$$

where:

$d x$ is the original length of the element;

$r$ is the radius of curvature due to load;

$y$ is the distance to point from neutral axis;

$e$ is the strain relative elongation of the beam or element.

The key is to determine the strain, because this parameter is measured by the designed system. After transforming, the strain can be described by the formula:

$$
e=-\frac{y}{r}
$$

The radius of curvature can be represented by Equation (4). When $f \ll 1$, the equation can be reduced.

$$
r=\frac{f^{2}+\left(\frac{l}{2}\right)^{2}}{2 f} \approx \frac{l^{2}}{8 f}
$$

where:

$f$ is the deflection of the beam;

$l$ is the length of the beam;

When $f \ll 1$, the equation can be reduced;

When substituted for Equation (2), it allows us to determine the strain (the minus is due to the bending moment direction).

$$
e=-\frac{y 8 f}{l^{2}}
$$


For a beam supported at two points, the maximum deflection $f$ can be presented by Formula (6).

$$
f=\frac{5}{384} \frac{q l^{4}}{E I}
$$

where:

$q$ is the uniform load per length unit of beam;

$E$ is the Young's modulus-material modulus of elasticity;

$I$ is the area moment of inertia.

The moment of inertia depends on the position of the figure's center of gravity in relation to a given axis. In monitored structures, the main girders usually have rectangular or I-beam cross-sections (Figure 9).

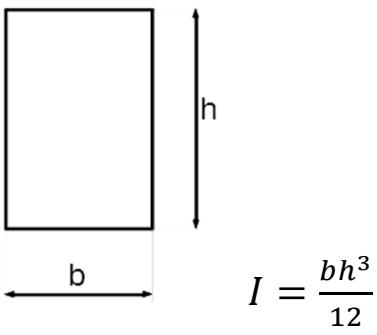

(a)

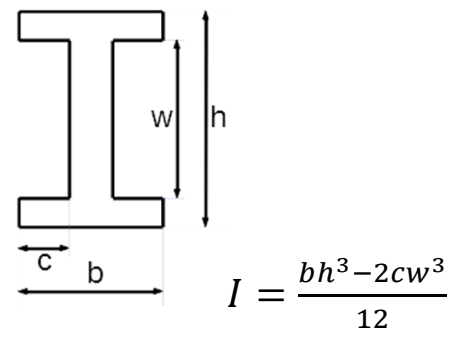

(b)

Figure 9. Cross section of typical beams and their area moment of inertia (I), (a) rectangular beam, (b) I-beam.

The maximum deflection of the main girder was provided by European Standard EN 1993-1-1 and the American Concrete Institute Standard. These values vary slightly, but it can be assumed that the dead load of the beam can cause a deflection:

$$
f_{\max }<\frac{1}{250}
$$

For further calculations we assume the following girder parameters: length $\mathrm{L}=10 \mathrm{~m}$, a rectangular cross-section with base $b=60 \mathrm{~mm}$ and height $\mathrm{h}=120 \mathrm{~mm}$. The material of the beam is structural steel, for which the Young's modulus $E=200 \mathrm{GPa}$. By substituting for expressions 2-7, we obtain:

The distance to point from neutral axis $y=0.06 \mathrm{~m}$;

The maximum deflection $f_{\max }=10 \mathrm{~m} / 250=0.04 \mathrm{~m}$;

The radius of curvature for maximum deflection $r=312.5 \mathrm{~m}$;

The strain $e=0.00192 \mathrm{~m} / \mathrm{m}=192$ ustrain;

The area moment of inertia $I=8.64 \times 10^{-6}$.

The maximum uniform load for the above parameters will be $q=2.65 \mathrm{kN} / \mathrm{m}$. When an I-beam is used $\left(\mathrm{h}=12 \mathrm{~mm} \mathrm{~b}=6 \mathrm{~mm} \mathrm{c}=2 \mathrm{~mm} \mathrm{w}=8 \mathrm{~mm}\right.$ ), the moment of inertia $\mathrm{I}=6.506 \times 10^{-6}$ and the maximum load will be $q=2.00 \mathrm{kN} / \mathrm{m}$. However, the mass of construction will be much lower.

\section{Tests and Results}

To minimize the interference induced in the cables between the sensors and the ADC, the node must be installed on the element on which the deformation is measured. In this case, it will be the main roof girder. The resolution of the measurement node is related to the resolution of the ADC and the sensitivity of the used strain gauges. In the case of the standard foil strain gauges made of constants, the gauge factor was about $K=2.15$, and the base resistance $R=120 \Omega$. The sensors work in differential half-bridge circuits. The output signal from the bridge circuit was sampled by $20 \mathrm{bits}$ of ADC. On the described node, the reference voltage for ADC was the same as the power bridge $U_{F S O}=$ 
$U_{H B}=3.3 \mathrm{~V}$. For such parameters, the resolution in resistance measurement is $\Delta R_{\min }(8)$. This value allows to determine the theoretical resolution of elongation measurement $e_{\min }(9)$. This allowed for a theoretical measurement resolution of $0.88 \mu$ strain for the half-bridge circuit (and $0.44 \mu$ strain for the full-bridge circuit).

$$
\begin{aligned}
\Delta R_{\text {min }} & =\frac{\left(\frac{U_{F S O}}{2^{20}}\right) 2 R}{U_{H B}} \\
e_{\text {min }} & =\frac{\Delta R_{\text {min }}}{2 R K}
\end{aligned}
$$

The polymeric sensors had a base resistance of $290 \mathrm{Ohms}$. The determined gauge factor was 3.9, which is almost twice as much as for the strain gauges made of constants. The theoretical resolution of measurement is $0.48 \mu$ strain for the half-bridge circuit (and $0.24 \mu$ strain for the full-bridge circuit). In a real system, the sensor will work on the half-bridge circuit because the obtained resolution is enough and the installation process is much easier.

From previous calculations, we know that the real elongations will be in the range from 0 to $192 \mu$ strain. Theoretically, both types of sensors can work in the system. If metal sensors are used, the measurement error resulting from the resolution is $0.46 \%$. The same error for carbon sensors is $0.25 \%$. However, during laboratory tests using a mechanical stand allowing for accurate deformations in the range from 0 to $157 \mu$ strain and a reference Nation Instruments NI-9237 strain bridge, it was noted that the polymer sensors work outside the range. The laboratory setup is presented in Figure 10.

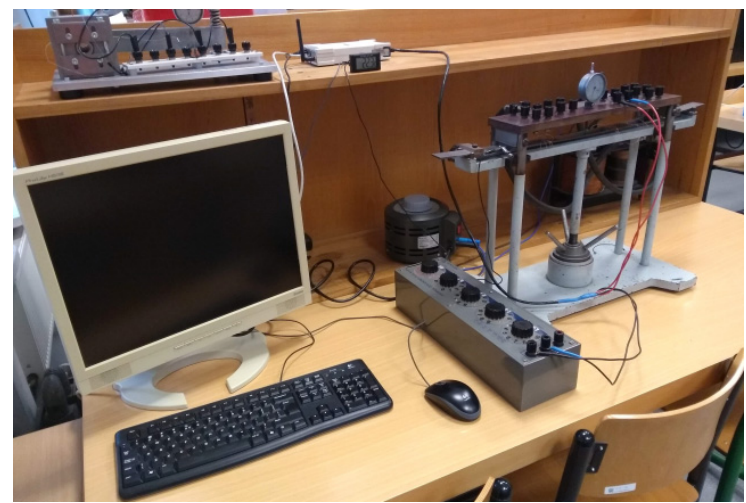

(a)

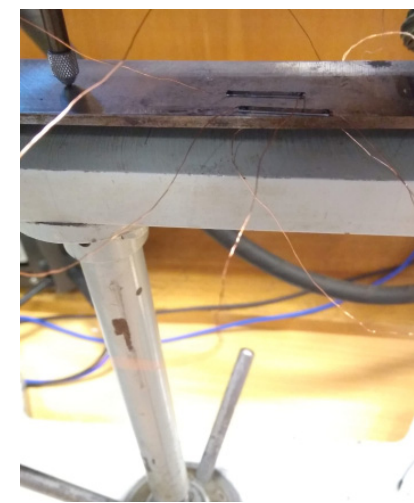

(b)

Figure 10. Laboratory setup to create and measure strain (a), and tested polymer sensor on the beam (b).

For the experiment, we prepared two pairs of polymeric strain gauges and two pairs of metal strain gauges. The strain gauges were glued to a standard steel beam with cyanoacrylate adhesive. All pairs of strain gauges allow for the construction of a differential half-bridge circuit. For each of the strain gauges, the factor was determined. During this experiment, we changed the reference beam tension to obtain strain from 0 to 157 ustrain.

While we were testing the polymer strain gauges, we noticed that, after exceeding 30-40 $\mu$ strain, the change in resistance is no longer linear. We repeated the experiments two times, and we obtained different results each time. Thus, it can be concluded that the material (carbon paints) used to make the sensors do not have a stable elastic module. The sensors worked behind the region of elastic deformation, which caused their permanent deformation according to Hooke's law [22]. This situation eliminates the polymer sensor from used in the designed system. However, printed sensors based on other conductive substances, e.g., silver inks, successfully perform the role of strain gauges, which was proven by Ando [23,24]. 
The same test procedure was repeated for metal strain gauges. The factor for each strain gauge is $\mathrm{K}_{1}=2.13, \mathrm{~K}_{2}=2.19, \mathrm{~K}_{3}=2.06 \mathrm{~K}_{4}=2.16$. This is consistent with strain gauges made of constants. The characteristics of both strain gauges are shown in Figure 11.

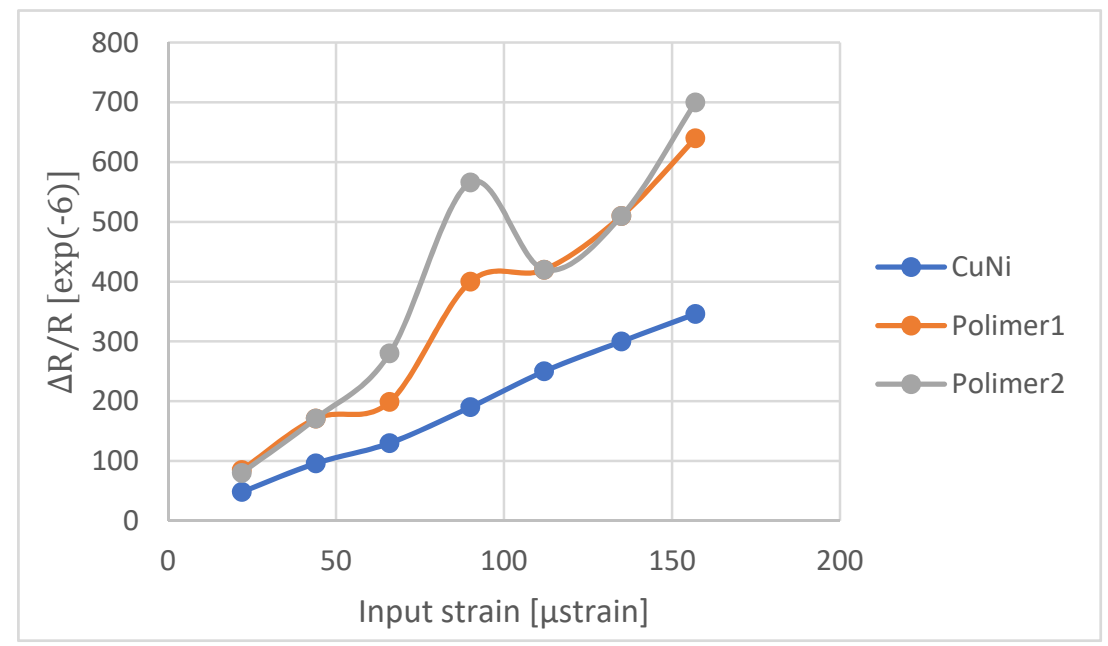

Figure 11. Determination of the strain gauge factor for constant and polymeric sensor.

We also determined the sensitivity of the half-bridge systems, which is presented in Figure 12. Both here and in further studies, we took into account only the strain gauges made of constants. Polymer strain gauges, due to the very narrow measuring range, were rejected.

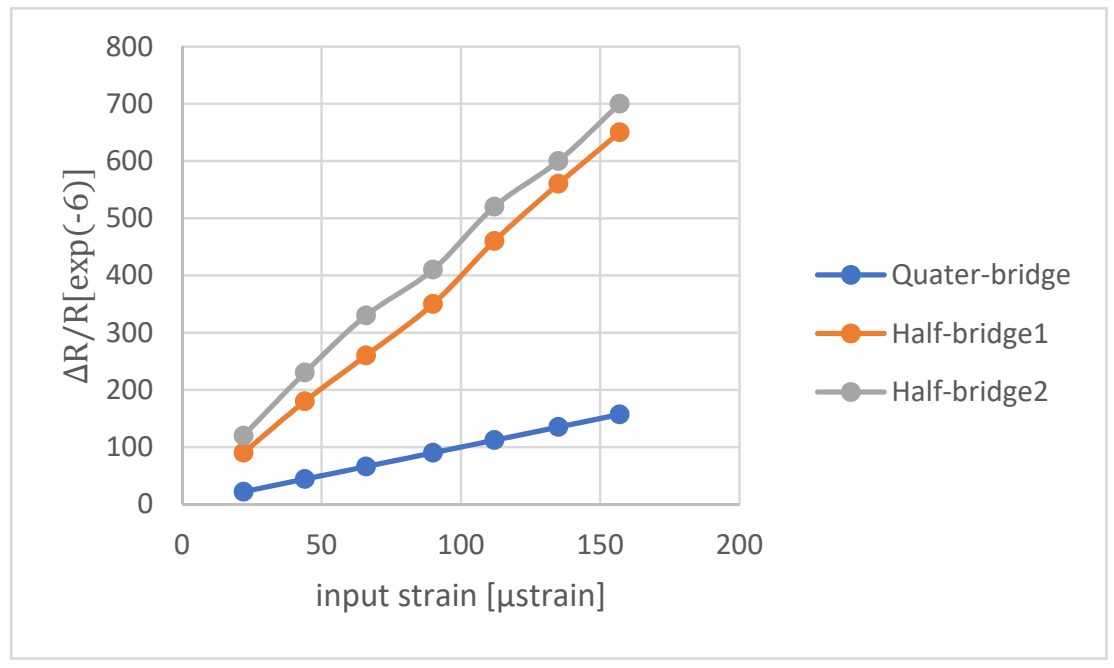

Figure 12. Sensitivity of quarter-bridge (2.16) and half-bridge (4.23) (435) circuit.

To estimate the precision of the measurement, we conducted an experiment in which the same stress of the reference beam was measured by the designed node and the reference bridge. The comparison of measurements made with the reference strain gauge bridge and the system sensor node is shown in Figure 13. We made two measurement series (s1, s2). To estimate the measurement error, we calculated the standard deviation, with regard to the ideal linear characteristics, and we received, respectively:

$\mathrm{SD}_{\text {Node_s1 }}=5.65 \mu$ strain;

$\mathrm{SD}_{\text {Node_s1 }}=4.68 \mu$ strain.

The relative error of the measurement was calculated from the standard deviation. For an expected measurement range of $192 \mu$ strain, it will cause a relative error of $2.5 \%$. As we can see, the actual measurement error is much greater than that resulting from the measurement resolution. However, 
this value allows the use of the constant strain gauge for stress measurement in the building condition assessment system.

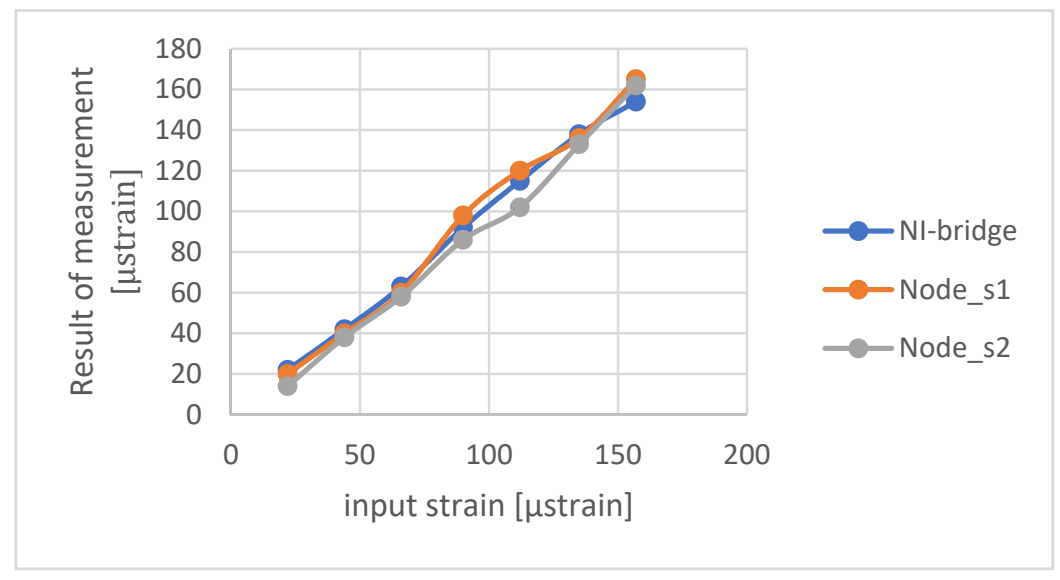

Figure 13. Comparison result of measurements from constructed node and NI 9237 strain bridge.

The communication between the node and the network hub has been verified. This communication structure has already been successfully used by us in a system for water quality monitoring [25]. The maximum communication span was $65 \mathrm{~m}$ in free space and $45 \mathrm{~m}$ inside the building. It is possible to increase the range at the expense of increasing the power of the transmitter, which is not advantageous, because it would shorten the node's operation on battery power supply. The energy efficiency of the node is one of the most important parameters of WSN [26]. It determines the necessity of system maintenance and the impact on its maintenance costs. In the system under consideration, the node was battery powered. The battery had an efficiency of $1200 \mathrm{mAh}(3.6 \mathrm{~V})$. The energy needed to perform one measurement is $9.2 \mathrm{~mJ}$. This is related to the average current consumption of $5.6 \mathrm{~mA}(\mathrm{U}=3.3 \mathrm{~V})$ and the length of time necessary for the measurement procedure of $0.5 \mathrm{~s}$. Based on this, it can be assumed that the node will be able to take up to $1.55 \mathrm{M}$ measurements. If the measurements are sent 6 times per minute, it allows for battery operation for 6 months. However, it should be noted that these are the results of calculations and the continuous operation of the node over a long period of time was not checked.

\section{Conclusions}

The wireless monitoring system for stress measurement presented in the article is predisposed to work as system for monitoring snow and wind load on steel roofs. The selection of components shows that the system is able to measure strain with $5.5 \mu$ strain error, and a time resolution of seconds. Such parameters allow the system to monitor dynamic stresses caused by, e.g., violent winds or strong precipitation. Such conditions, combined with snow, are the cause of many building disasters. Hazards caused by the above conditions cannot be detected by methods based on measuring the density of snow. The proposed system improves monitoring of the condition of buildings and, consequently, improves the safety of the occupants.

Currently, the system has been tested in laboratory conditions. We checked the resolution and measurement error (5.5 $\mu$ strain), which gives a relative error of $2.5 \%$ for the expected elongation range. We also checked the communication range between the node and the access point (45 $\mathrm{m})$. This allows the monitoring of buildings up to $2000 \mathrm{~m}^{2}$ of roof area. We have also estimated that the WSN nodes will run for 6 months on battery power. After the completion of the laboratory work, we plan to implement the system on a real object-a steel warehouse.

Funding: This research was funded by Institute of Theory of Electrical Engineering, Measurement and Information Systems, Faculty of Electrical Engineering, Warsaw University of Technology. 
Conflicts of Interest: The authors declare no conflict of interest.

\section{References}

1. Işik, E.; Ülker, M.; Aydin, M.C. Stress Analysis of Steel Roof Trusses According To Different Snow Loads. In Proceedings of the 3rd CEPPIS International Scientific Conference on Civil Engineering: Present Problems, Innovative Solutions (CEPPIS2017), Bydgoszcz, Poland, 31 May 2017.

2. European Standard, EN 1990-2002 +A1. Basis of Structural Design; European Committee for Standardization: Brussels, Belgium, 2005.

3. Diamantidis, D.; Sykora, M.; Lenzi, D. Optimising Monitoring: Standards, Reliability Basis and Application to Assessment of Roof Snow Load Risks. Struct. Eng. Int. 2018, 28, 269-279. [CrossRef]

4. European Standard, EN 1991-1-3. Actions on Structures -Part 1-3: General Actions -Snow Loads; European Committee for Standardization: Brussels, Belgium, 2009.

5. Construction Disasters, General Office of Building, Warsaw. Available online: https://www.gunb.gov.pl/ strona/katastrofy-budowlane (accessed on 28 February 2020).

6. Pirazzini, R.; Leppänen, L.; Picard, G.; Lopez-Moreno, J.I.; Marty, C.; Macelloni, G.; Kontu, A.; Von Lerber, A.; Tanis, C.M.; Schneebeli, M.; et al. European In-Situ Snow Measurements: Practices and Purposes. Sensors 2018, 18, 2016. [CrossRef] [PubMed]

7. Zuo, G.; Dou, Y.; Lei, R. Discrimination Algorithm and Procedure of Snow Depth and Sea Ice Thickness Determination Using Measurements of the Vertical Ice Temperature Profile by the Ice-Tethered Buoys. Sensors 2018, 18, 4162. [CrossRef] [PubMed]

8. Pivot, F.C. C-Band SAR Imagery for Snow-Cover Monitoring at Treeline, Churchill, Manitoba, Canada. Remote Sens. 2012, 4, 2133-2155. [CrossRef]

9. Paloscia, S.; Pettinato, S.; Santi, E.; Valt, M. COSMO-SkyMed Image Investigation of Snow Features in Alpine Environment. Sensors 2017, 17, 84. [CrossRef] [PubMed]

10. Poussin, C.; Guigoz, Y.; Palazzi, E.; Terzago, S.; Chatenoux, B.; Giuliani, G. Snow Cover Evolution in the Gran Paradiso National Park, Italian Alps, Using the Earth Observation Data Cube. Data 2019, 4, 138. [CrossRef]

11. Liang, H.; Huang, X.; Sun, Y.; Wang, Y.; Liang, T. Fractional Snow-Cover Mapping Based on MODIS and UAV Data over the Tibetan Plateau. Remote Sens. 2017, 9, 1332. [CrossRef]

12. Kwanthong, N.; Onsri, N.; Inkerd, S.; Klompong, N. The wireless sensor network monitoring of sea level and wind speed. In Proceedings of the 2017 9th International Conference on Information Technology and Electrical Engineering (ICITEE), Phuket, Thailand, 12-13 October 2017; pp. 1-4.

13. Ghahramani, A.; Zhu, M.; Przybyla, R.J.; Andersen, M.P.; Galicia, P.J.; Peffer, T.E.; Zhang, H.; Arens, E. Measuring Air Speed with a Low-Power MEMS Ultrasonic Anemometer via Adaptive Phase Tracking. IEEE Sens. J. 2019, 19, 8136-8145. [CrossRef]

14. Gill Anemometer Portfolio. Available online: http://www.gill.co.uk/products/anemometer/anemometer.htm (accessed on 28 February 2020).

15. Caetano, E.; Cunha, Á.; Moutinho, C.; Hu, W. Dynamic monitoring of civil engineering structures. In Proceedings of the 2015 3rd Experiment International Conference (exp.at'15), Ponta Delgada, Portugal, 2-4 June 2015; pp. 79-85.

16. Basili, M.; Buttarazzi, B.; Oguni, K. Application of a Wireless Sensor Network Technology Based on GPS for Structural Health Monitoring. In Proceedings of the 2013 Workshops on Enabling Technologies: Infrastructure for Collaborative Enterprises, Hammamet, Tunisia, 17-20 June 2013; pp. 186-189.

17. Arcadius Tokognon, C.; Gao, B.; Tian, G.Y.; Yan, Y. Structural Health Monitoring Framework Based on Internet of Things: A Survey. IEEE Internet Things J. 2017, 4, 619-635. [CrossRef]

18. Dziadak, B.; Siek, M. Wireless Network Node to Monitor Stress in Steel Structures. Elektronika ir Elektrotechnika 2016, 22, 46-51. [CrossRef]

19. Yao, J.; Tian, H. Design of roof abscission layer wireless monitoring system based on $433 \mathrm{MHz}$ RF technology. In Proceedings of the 2014 12th International Conference on Signal Processing (ICSP), Hangzhou, China, 19-23 October 2014; pp. 2190-2193.

20. Sarwar, M.Z.; Park, J.-W. Bridge Displacement Estimation Using a Co-Located Acceleration and Strain. Sensors 2020, 20, 1109. [CrossRef] [PubMed] 
21. Chen, S.-Z.; Wu, G.; Xing, T. Deflection monitoring for a box girder based on a modified conjugate beam method. Smart Mater. Struct. 2017, 26, 085034. [CrossRef]

22. Tabernero, A.; Baldino, L.; Cardea, S.; Martín del Valle, E.; Reverchon, E. A Phenomenological Approach to Study Mechanical Properties of Polymeric Porous Structures Processed Using Supercritical $\mathrm{CO}_{2}$. Polymers 2019, 11, 485. [CrossRef] [PubMed]

23. Andò, B.; Baglio, S.; Bulsara, A.R.; Emery, T.; Marletta, V.; Pistorio, A. Low-Cost Inkjet Printing Technology for the Rapid Prototyping of Transducers. Sensors 2017, 17, 748. [CrossRef] [PubMed]

24. Ando, B. Inkjet printing: A real opportunity for the next generation of low-cost sensors. IEEE Instrum. Meas. Mag. 2013, 16, 44-48. [CrossRef]

25. Dziadak, B.; Makowski, L.; Michalski, A. Some Practical Problems of Communications Reliability in Enviromental Monitoring Systems. Metrol. Meas. Syst. 2013, 20, 337-350. [CrossRef]

26. Dziadak, B.; Michalski, A. Evaluation of the Hardware for a Mobile Measurement Station. IEEE Trans. Ind. Electron. 2011, 58, 2627-2635. [CrossRef]

(C) 2020 by the author. Licensee MDPI, Basel, Switzerland. This article is an open access article distributed under the terms and conditions of the Creative Commons Attribution (CC BY) license (http://creativecommons.org/licenses/by/4.0/). 